\title{
RESSIGNIFICAR A DOCÊNCIA DIANTE DAS TECNOLOGIAS DE INFORMAÇÃO E COMUNICAÇÃO
}

\author{
Acácio Silveira França* \\ Elizabeth Adorno de Araújo **
}

\begin{abstract}
RESUMO
Este artigo teve como base os resultados de uma pesquisa sobre a atividade docente diante do uso das tecnologias de informação e comunicação. A metodologia utilizada foi de uma abordagem qualitativa, e reuniu um estudo bibliográfico sobre o tema e a realização de entrevistas semi-estruturadas, com o objetivo de discutir a necessidade de que os cursos de formação de professores tenham um espaço de reflexão e de orientação aos futuros docentes com vistas à inserção das tecnologias de informação e comunicação na Educação, dentro de uma perspectiva de revalorizar e ressignificar a atividade docente.
\end{abstract}

PALAVRAS-CHAVE: Docência. Formação de Professores. Globalização. Inovação. Tecnologia.

\begin{abstract}
This article presents the results of a research about teaching in face of the use of information and communication technologies. The methodology used had a qualitative approach, articulating a bibliographic study about the theme and the realization of semi-

\footnotetext{
* Mestre em educação pela PUC-Campinas. E-mail: acacio@hotmail.com

** Professora do Programa de Mestrado em Educação da PUC-Campinas; membro do grupo de pesquisa ICCON. E-mail: elizabethe@dgnet.com.br
} 
structured interviews, with the aim of discussing the need of a space in teaching education courses for reflection and orientation of future teachers, focused on the insertion of information and communication technologies in Education, within a perspective of giving new values and new meanings for the teaching activity.

KEYWORDS: Teaching. Teacher Education. Globalization. Innovation. Technology.

\section{Introdução}

Este artigo teve como base os resultados das entrevistas realizadas com quatro pesquisadores sobre a atividade docente diante do uso das tecnologias de informação e comunicação, e foi extraído de uma dissertação de mestrado em Educação.

O objetivo do estudo teve como perspectiva a revalorização e a ressignificação da prática docente, considerando o professor como imprescindível nos processos de ensino e de aprendizagem.

Em termos de contribuição à Educação, partimos do princípio que o significado atual atribuído ao papel do docente precisa ser revisto e levantamos a hipótese de que a profusão das tecnologias no meio educacional é um dos elementos capazes de ressignificar a docência e gerar melhorias na qualidade do ensino.

Nesse sentido, citamos Boaventura dos Santos (2005, p. 330) ao descrever a utopia como sendo o único caminho para pensar o futuro:

O único caminho para pensar o futuro parece ser a utopia. E por utopia entendo a exploração, através da imaginação, de novas possibilidades humanas e novas formas de vontade, e a oposição da imaginação à necessidade do que existe, só porque existe, em nome de algo radicalmente melhor porque vale a pena lutar. 
Compreendemos que há necessidade de inovação no ensino, mas a Escola ainda parece distante desse propósito, não conseguindo acompanhar as expectativas da sociedade atual, em especial dos jovens e das crianças.

A Escola precisa ser sensível às novas exigências do mundo informatizado, e desenvolver uma formação condizente à realidade. As considerações obtidas nas entrevistas apontam essa possibilidade e reconhecem que os cursos de formação de professores precisam ter um espaço de reflexão e de orientação com vistas à inserção das tecnologias de informação e comunicação.

\section{Metodologia}

A pesquisa foi desenvolvida dentro de uma abordagem qualitativa, reunindo entrevistas semi-estruturadas e um estudo bibliográfico sobre o tema:

Entre os mais diversos significados, conceituamos abordagem qualitativa ou pesquisa qualitativa como sendo um processo de reflexão e análise da realidade através da utilização de métodos e técnicas para compreensão detalhada do objeto de estudo em seu contexto histórico e/ou segundo sua estruturação. Esse processo implica em estudos segundo a literatura pertinente ao tema, observações, aplicação de questionários, entrevistas e análise de dados, que deve ser apresentada de forma descritiva. (OLIVEIRA, 2007, p. 37)

Esse conceito exprime a essência do nosso trabalho, na medida em que buscamos na literatura estudos relacionados ao tema escolhido, realizamos entrevistas e fizemos a análise e a apresentação dos dados.

Seguindo essas orientações, juntamente com as diretrizes do Comitê de Ética da PUC-Campinas, convidamos para as entrevistas 
doze pesquisadores que trabalham em universidades localizadas no Estado de São Paulo, sendo que o teor das questões abordadas não teve nenhuma relação com as instituições.

Para critério de escolha dos entrevistados levamos em conta as pesquisas ou publicações relacionadas à formação de professores no contexto atual, além de certa afinidade ou interesse pelo tema das tecnologias de informação e comunicação e que aceitassem voluntariamente participar.

Das doze pessoas contatadas chegamos a quatro entrevistas, dois pesquisadores e pesquisadoras que aceitaram participar. Em relação à graduação, as pesquisadoras se formaram em Pedagogia e os pesquisadores em Matemática.

O grupo possui em comum o doutorado em Educação, além de uma trajetória marcante no ensino superior, incluindo experiência em programas de pós-graduação e um profícuo trabalho de pesquisa acadêmica, abordando a formação de professores.

\section{Resultados da pesquisa}

Após a realização das entrevistas, procedemos à etapa de análise dos dados, bem como a interação dos resultados das entrevistas com a base teórica:

Na fase de classificação de dados são definidas as categorias empíricas, decorrentes dos tópicos das entrevistas e de cada questão aplicada na pesquisa de campo. As respostas obtidas devem ser classificadas criteriosamente, observando-se as respostas similares ou convergentes para se definirem as unidades de análise que são trabalhadas à luz da fundamentação teórica. (OLIVEIRA, 2007, p.103)

Os dados foram classificados em eixos temáticos, e tiveram origem nas questões respondidas: 1) A escola e os alunos; 2) A escola e os professores; 3) Políticas educacionais; 4) Exclusão digital e 
algemas digitais; 5) Uma nova concepção de tempo e espaço; 6) Ressignificar o papel do professor.

\section{A escola e os alunos}

Neste primeiro eixo foram apresentadas considerações no sentido de que os alunos dominam as tecnologias melhor do que os professores. Uma das entrevistas chama a atenção para o contraste entre o mundo do aprendiz e a escola:

O mundo do jovem, o mundo do adulto, o mundo do aprendiz é um mundo cercado de tecnologia. Quando ele vai pra escola, a escola não pode representar um ambiente totalmente desligado do mundo dele. E se ele sai desse mundo cheio de tecnologia e vai para a escola e a tecnologia que ele encontra é o quadro negro e giz, lápis e papel, livro impresso é obvio que ele está mal situado nesse ambiente. Porque o ambiente dele, a vida dele, 24 horas, das quais algumas horas por semana, nem todos os meses, ele passa na escola, o resto ele está no mundo real, e o mundo real é impregnado de tecnologia. Eu acho que esse é um ponto: a escola tem que ser adaptada ao mundo real.

Moran (2004, p. 21) lembra que as crianças e os jovens estão sintonizados com as tecnologias. Atribuímos isso ao fato de pertencerem a uma geração informatizada, enquanto as gerações anteriores precisam adaptar-se a ela.

Outro aspecto sobre os alunos é a tendência de que a interação social ocorra cada vez mais de forma virtual. Segundo os entrevistados as pessoas estão se conhecendo e até casando, e muitos casamentos estão dando certo; o espaço virtual tem sido utilizado para mobilizar as pessoas em torno de um propósito político ou social; têm as salas de "bate-papo" e outras formas de entretenimento.

Uma das entrevistas, no entanto, sugere que os modos de convivência tradicionais ainda trazem um tipo de formação mais

Educ. e Filos. Uberlândia, v. 23, n 45, p. 185-200, jan./jun. 2009 
integradora, mais interativa. E destaca certa contradição:

Ao mesmo tempo em que tem um lado, que é poder se comunicar, fazer contato com uma pessoa que está lá no Japão e com outro que está lá na Europa, independente de ter o domínio da língua estrangeira ou não, o que está ali do seu lado você não convive com ele.

Lévy (2000, p. 167), discorrendo sobre a interconexão dos computadores do planeta, afirma a tendência desse processo tornarse a principal infra-estrutura de produção, transação e gerenciamento econômicos e afirma que qualquer política de educação terá que levar isso em conta:

O ciberespaço, suas comunidades virtuais, suas reservas de imagens, suas simulações interativas, sua irresistível proliferação de textos e de signos, será o mediador essencial da inteligência coletiva da humanidade. Com esse novo suporte de informação e de comunicação emergem gêneros de conhecimento inusitados, critérios de avaliação inéditos para orientar o saber, novos atores na produção e tratamento dos conhecimentos. Qualquer política de educação terá que levar isso em conta.

Não podemos negar a tendência dos encontros ocorrerem mais de forma virtual do que presencial - daí a necessidade de buscarmos novos conhecimentos em benefício da docência. Mas essa busca deve ocorrer com critério e reflexão.

\section{A escola e os professores}

As considerações de uma das entrevistas assinalam que o professor está preparado para trabalhar em um mundo que não existe mais, pois quando começa atuar a tecnologia mudou muito, evoluiu muito. Outra entrevista refere-se à resistência de alguns professores à inovação que provém das tecnologias. 
Cunha (2006, p. 28) lembra que a importância e o significado do papel do professor não dependem exclusivamente dele, e que esses fatores variam em função de valores e interesses de cada época:

A sociedade contemporânea já produziu a idéia do professorsacerdote, colocando a sua tarefa ao nível de missão, semelhante ao trabalho dos religiosos. Amistificação do professor foi produto social e interferiu no seu modo de ser e de agir. Evoluiu posteriormente a idéia do professor como profissional liberal, privilegiando o seu saber específico e atribuindo-lhe uma independência que, na prática, talvez nunca tivesse alcançado.

Há necessidade, então, de reflexão em torno das práticas docentes, evitando o risco de permanecer no passado e, conseqüentemente, inviabilizar propostas de inovação, sejam elas provenientes das tecnologias ou não.

Sobre a formação para uso das tecnologias as entrevistas sugerem que os cursos devem discutir a inserção das tecnologias de informação e comunicação. Uma entrevistada relatou uma experiência que está ocorrendo em sua universidade:

É um novo curso de matemática, uma nova proposta, que forma o professor de matemática com habilitação em informática educativa, começa esse ano e tem essa disciplina. Isso deveria ser seguido por todos os cursos de licenciatura. Isso em relação ao professor na formação, já na graduação.

Enfatizamos, então, que a participação dos cursos de formação de professores é imprescindível para que a inserção das tecnologias no ensino ocorra de maneira satisfatória, aproximando a escola do mundo atual. 


\section{Políticas educacionais}

Com respeito à existência de políticas e programas de governo com vistas à inserção das tecnologias as opiniões se dividiram, mas um entrevistado referiu-se às diretrizes do MEC, aos pareceres e resoluções que enfatizam as tecnologias, mas salientou que na hora de efetivar esses programas existe uma grande lacuna.

Kenski (2006, p. 85) comenta alguns impasses nesse processo, declarando que o governo e o setor privado investem maciçamente na informatização das escolas e no treinamento de professores, mas o essencial ainda carece ser feito.

Existem, de fato, políticas voltadas ao uso das tecnologias, mas ainda não conseguiram alcançar os objetivos e se perdem em algum ponto do processo.

Libâneo (1998, p. 67), ao analisar os impactos das tecnologias no contexto educacional, constata resistência por parte dos educadores e diz que há razões culturais, políticas e sociais para isso, e que geram atitudes difusas e ambivalentes.

Aresistência foi um dos aspectos apontados pelos entrevistados, inclusive alguns se referiram ao problema dos laboratórios de informática fechados. São exemplos de atitudes difusas e ambivalentes, conforme assinaladas pelo autor acima.

\section{Exclusão digital e algemas digitais}

Reconhecemos que uma parte significativa da sociedade está impossibilitada de participar dos benefícios das tecnologias; de outro, existem pessoas que ficam à disposição das organizações, através do celular ou das diversas formas de comunicação e trabalho pelo computador, e podem ser encontradas a qualquer hora.

Em relação à exclusão, um dos entrevistados reconhece que esse fato está ligado a esse modelo de capitalismo que estamos vivendo e considera isso inadmissível:

Educ. e Filos. Uberlândia, v. 23, n 45, p. 185-200, jan./jun. 2009 
Esse modelo de capitalismo se constrói a partir da exclusão. Grandes fortunas se construíram a partir de gente que trabalhou por nada, e aí tem toda a questão da escravidão. Foi construído nesse modelo capitalista que é o modelo atual, que nós estamos vivendo. Isso é inadmissível na minha percepção. Esse modelo capitalista não pode continuar. Bom, esse modelo produziu uma grande tecnologia. Claro, há exclusão, porque ele é baseado na exclusão. Você poderia produzir alguma coisa a um preço que é um décimo. Mas se você colocar o preço real o seu lucro diminui. Para poder ter mais lucro o que você faz? Você faz uma competição.

Outra entrevista destaca que o desenvolvimento tecnológico aumenta o distanciamento entre as pessoas que têm acesso a ele e as que não têm.

Alarcão $(2001$, p. 9) faz referência às terríveis conseqüências dessa exclusão, tendo em vista que a era industrial está sendo substituída pela era do conhecimento e da informação.

Martínez (2004, p. 95) reconhece um papel relevante nas tecnologias de informação e comunicação, mas se mostra preocupado com os efeitos inversos, isto é, que as tecnologias assinalem ainda mais as diferenças em termos de acesso.

Em relação às "algemas digitais", empregamos essa metáfora pensando em situações que o uso de determinadas tecnologias resultam em acréscimo de trabalho, deixando as pessoas a qualquer hora à disposição das organizações.

$\mathrm{O}$ primeiro entrevistado entende que as organizações são sábias em buscar para si os benefícios, mas deposita confiança na escola em formar as pessoas não para reproduzir esse modelo, mas para questionar e propor algo melhor.

A segunda entrevistada compara os modernos equipamentos à caneta parker, a uma bela agenda e entende que essa algema, às vezes, é um benefício. $\mathrm{O}$ terceiro entrevistado diz que as organizações têm se aproveitado para agilizar uma série de procedimentos, mas que com o 
domínio da tecnologia ela se torna mais envolvente.

A quarta entrevistada diz que já tem ouvido muito esse termo e esclarece que as algemas estão com a elite da população, e não com os operários:

Esses dias eu estava vendo uma reportagem que dizia: Antes se trabalhava das 9 às 5, agora a gente trabalha das 5 às 9. - Agora, quem é essa camada que trabalha das 5 às 9? - Não é o operário, porque ele tem os seus horários de trabalho regulado pelo apito da fábrica, pelo seu cartão de ponto. Desse modo, eu acho que essa generalização de que teríamos mais tempo de ócio, está abarcando uma faixa da população, que é justamente a que menos tem acesso a bens culturais.

De Masi (2000) foi um dos sociólogos a defender idéia de ócio por conta do desenvolvimento tecnológico, tempo que seria dedicado à cultura, lazer e atividades criativas. Na prática, porém, algumas pessoas estão trabalhando mais.

A observação de que a classe trabalhadora tem o seu horário regulado enquanto a elite trabalha mais e tem as algemas pelo fato de poder ser encontrada a qualquer hora e em qualquer lugar, chama a atenção.

Não sabemos se tal inversão pode ser um caminho para uma sociedade mais justa, e se o ócio para a classe trabalhadora trará os benefícios preconizados por De Masi (2000), mas é algo para ser estudado de forma aprofundada.

\section{Uma nova concepção de tempo e espaço}

Neste eixo discutimos a revalorização do tempo e espaço escolares, tendo em vista o crescimento das modalidades de ensino a distância e as implicações disso em relação ao trabalho docente. As respostas reforçam a necessidade de inovação, e o professor pode 
incorporar práticas empregadas no ensino a distância.

$O$ primeiro entrevistado exemplifica que não adianta o professor falar sobre a Amazônia, de uma forma estática, ou usar um retroprojetor, se no dia anterior o aluno viu um belíssimo filme sobre a Amazônia. Enfatiza o momento do encontro, na aula, como uma oportunidade maravilhosa, não para repetir o que pode ser dado por outros meios, mas para analisar criticamente aquilo que o aluno já viu.

Você quer coisa mais maravilhosa do que ter essa hora na escola, em que todos os alunos estão juntos, marcada regularmente? Toda semana, tal hora, você vai encontrar os alunos e os professores juntos. Encontrar pra fazer o quê, pra fazer o que ele pode fazer ou que ele já faz de uma forma mais dinâmica, mais bonita?! Você aproveita o momento do encontro para refletir sobre essa informação que ele já recebe e não pra dar a mesma informação.

A segunda entrevista lembra que é possível dar continuidade ao trabalho com os alunos através de uma aula virtual ou quando encaminha um texto para leitura e cita a comunicação permanente com os alunos, por e-mail.

O terceiro entrevistado lembra dos jogos educativos, que para muitos serve para passar o tempo, mas no contexto educacional pode ser algo muito interessante.

Para a quarta entrevistada, nos cursos presenciais a comunicação permanente ainda está bem distante.

Kenski (2007, p. 124) deposita muita confiança nessa transformação, e destaca que o uso intensivo das tecnologias digitais e das redes transforma as dimensões da Educação e dá à escola "o tamanho do mundo".

Lévy (2000, p. 158) propõe ao professor a incorporação de certas técnicas, que já vem sendo exploradas pelo ensino a distância: 
A EAD explora certas técnicas de ensino a distância, incluindo as hipermídias, as redes de comunicação interativa e todas as tecnologias intelectuais da cibercultura. Mas o essencial se encontra em um novo estilo de pedagogia, que favorece ao mesmo tempo as aprendizagens personalizadas e a aprendizagem coletiva em rede. Nesse contexto, o professor é incentivado a tornar-se um animador da inteligência coletiva de seus grupos de alunos em vez de um fornecedor direto de conhecimentos.

As entrevistas e os autores citados reforçam a necessidade de mudança. Daí a importância dos cursos presenciais incorporarem algumas práticas do ensino a distância. Se o professor desenvolver estratégias para lidar com as tecnologias, terá a oportunidade de ampliar o tempo e o espaço de suas práticas, além de atender as expectativas dos alunos que se identificam com uma forma mais dinâmica de trabalho.

Na medida em que o aluno é incentivado a acessar previamente os conteúdos curriculares, valendo-se inclusive da Internet, a escola passa a ter mais tempo para a reflexão, tornando significativo o encontro entre professor e alunos.

\section{Ressignificar o papel do professor}

Neste último eixo incluímos as considerações dos entrevistados segundo a perspectiva de que as tecnologias podem contribuir na prática docente, dando um novo significado ao papel do professor.

Um dos entrevistados recordou o tempo do professor repetidor, mas destacou a necessidade desse professor reexaminar o seu papel:

Houve um tempo que o professor era um repetidor. Por quê? Porque as coisas que ele repetia eram de difícil acesso. E o professor tem 
uma formação mais longa, leu muitos livros e sabe muita coisa, os alunos não teriam acesso a tudo isso, não daria para chegar. Hoje é muito raro que o professor tenha lido alguma coisa que não pode ser acessado pelo aluno. Muito raro. - Então, o que é que ele tem, ele tem que reexaminar o seu papel. - Onde que a máquina não conseguiu chegar? Não conseguiu chegar a ser gente! - Ela é rápida, resolve problemas até, faz um monte de coisa de uma forma eficiente, rápida. A única coisa é que ela é fria, ela não tem emoção, ela não é gente. $\mathrm{O}$ professor tem que preencher essa lacuna da máquina.

Dois entrevistados fizeram considerações em torno da necessidade de capacitação dos professores, além de pesquisarem sobre o que as tecnologias podem oferecer à sua área de conhecimento.

A última entrevista frisou a importância do professor, destacando que os recursos estão postos e devem ser utilizados sempre que necessário, mas têm que ter um encaixe num conjunto de trabalho, e quem têm que comandar isso é o professor:

$\mathrm{Eu}$ sou uma defensora da função docente. Eu acho que essa é uma função que não pode acabar, e não é por uma questão corporativista, é porque é o contato humano que é diferente do que você simplesmente pegar o livro e estudar pelo livro, pegar uma fita e estudar pela fita. São recursos bons, eu não os nego. Eu acho que leitura é fundamental, sempre, seja por um modo ou por outro. Ver um filme é uma coisa boa, é bom trazer um filme de vez em quando para a classe, para discutir. Assistir um vídeo, por exemplo, de uma conferência que alguém fez, é uma coisa boa. Utilizar Internet é uma coisa boa. São recursos que estão postos, e podem e devem ser utilizados sempre que for necessário, mas eles têm que ter um encaixe no conjunto de trabalho, e quem têm que comandar isso é o professor. 
Argumenta, ainda, quanto à importância do contato do aluno com o professor:

O contato com o professor eu acho que é muito fundamental exatamente por conta dos modos de pensar, dos modos de sentir, dessa questão de você poder por o filme e parar o filme e falar: Presta atenção nisso! - Chamar a atenção pra certas coisas, para ir levando a esse processo reflexivo, ir levando a esse problema analítico, crítico, a respeito do mundo. E se você faz isso numa situação não-presencial, você pode até colocar uma tarefa: Analise criticamente o filme. - Ou, você pode colocar uma tarefa: O que isso suscitou em você, comente tal coisa assim, assim. - Mas você nunca sabe o retorno que isso tem pra pessoa, ou com que base, com que critério ele fez a análise, pra você poder discutir com ele.

Aprendemos com as leituras e com as entrevistas que não cabe mais o professor repetidor - é preciso conhecer recursos e adequar o que existe a cada área, bem como orientar os alunos no uso das tecnologias.

Há necessidade, também, de maior envolvimento das instituições formadoras, por meio de um amplo debate, e que a figura do professor continua imprescindível, e as tecnologias devem vir a favor e não contra o professor.

\section{Considerações finais}

As entrevistas e o referencial teórico apontam para a capacidade das tecnologias de informação e comunicação contribuírem para um ensino de melhor qualidade. Nesse sentido, inferimos que as tecnologias podem beneficiar a prática docente e que um novo significado para o papel do professor se faz necessário devido ao próprio desenvolvimento tecnológico, à globalização e tantos outros fatores que apontam para uma realidade incontestável: o mundo 
mudou e tal fato implica em inovação na escola e na maneira dos professores exercerem a docência.

As possibilidades com a inserção das tecnologias geram algumas condições de aproximar o mundo da escola da realidade atual, mas para chegarmos a um resultado efetivo, alguns aspectos são fundamentais, tais como: capacitação dos professores; adequação dos cursos de formação; programas e políticas de governo que não se limitem a determinadas etapas, mas que se concretizem e que tenham uma relação com propósitos mais integrados, entre outros.

Sendo capaz de acompanhar mudanças assim tão profundas, a escola adquire maior relevância, e pode oferecer mais do que cursos determinados, ao final dos quais os alunos se formam, constituindose numa realidade presente ao longo da vida das pessoas, de modo que as duas coisas (vida e Educação) se integrem continuamente.

Visualizamos, dessa forma, a possibilidade de revalorização do tempo e espaço escolares com a inserção das tecnologias de comunicação e informação.

\section{Referências}

ALARCÃO, Isabel (Org.). Escola reflexiva e nova racionalidade. Porto Alegre: Artmed, 2001.

CUNHA, Maria Isabel. O bom professor e sua prática. $18^{a}$ edição. Campinas: Papirus, 2006.

DE MASI, Domenico. O ócio criativo. $10^{\mathrm{a}}$ edição. Rio de Janeiro: Sextante, 2000.

KENSKI, Vani Moreira. Educação e tecnologias: o novo ritmo da informação. Campinas: Papirus, 2007.

. Tecnologias e ensino presencial e a distância. Campinas: 
Papirus, 2006.

LEVY, Pierre. Cibercultura. 2a edição. São Paulo: editora 34, 2000.

LIBÂNEO, José Carlos. Adeus professor, adeus professora? Novas exigências educacionais e profissão docente. São Paulo: Cortez, 1998.

MARTÍNEZ, Jorge H. Gutiérrez: novas tecnologias e o desafio da educação. In: TEDESCO, Juan C. (Org.). Educação e novas tecnologias: esperança ou incerteza? São Paulo: Cortez e Unesco, 2004, p. 95-108.

MORAN, José Manuel. Ensino e aprendizagem inovadores com tecnologias audiovisuais e telemáticas. In: MORAN, José M., MASETTO, Marcos M. e BEHRENS, Marilda A. Novas tecnologias e mediação pedagógica. Campinas-SP: Papirus, 2004, p. 11-65.

OLIVEIRA, Maria Marly. Como fazer pesquisa qualitativa. Petrópolis: Vozes, 2007.

SANTOS, Boaventura de Souza. A crítica da razão indolente: contra o desperdício da experiência. $5^{\text {a }}$ edição. São Paulo: Cortez, 2005.

Data de Registro 07/04/08

Data de Aceite 06/10/08

Educ. e Filos. Uberlândia, v. 23, n 45, p. 185-200, jan./jun. 2009. 